\title{
Thioredoxin Binding Protein-2 Inhibits Excessive Fetal Hypoglycemia During Maternal Starvation by Suppressing Insulin Secretion in Mice
}

\author{
HARUTA MOGAMI, SHIGEO YURA, KEIJI TATSUMI, TSUYOSHI FUJII, KOHEI FUJITA, KAZUYO KAKUI, EIJI KONDOH, \\ TAKUYA INOUE, SHINGO FUJII, JUNJI YODOI, AND IKUO KONISHI
}

\begin{abstract}
Department of Gynecology and Obstetrics [H.M., S.Y., K.T., T.F., K.F., K.K., E.K., I.K.], Kyoto University Graduate School of Medicine, Kyoto 606-8507; Department of Gynecology and Obstetrics [T.I., S.F.], National Hospital Organization, Kyoto Medical Center, Kyoto 612-8555; Department of Biological Responses, Laboratory of Infections and Preventions [J.Y.], Institute for Virus Research, Kyoto University, Kyoto 606-8507; Precursory Research for Embryonic Science and Technology (PRESTO) [S.Y.], Japan Science and Technology Agency (JST), Tokyo 102-0075, Japan
\end{abstract}

\begin{abstract}
Glucose is a major fuel for fetal development. Fetal blood glucose level is mainly dependent on maternal blood glucose concentration, though it is also regulated by fetal insulin level. Thioredoxin binding protein-2 (TBP-2), which is identical to vitamin D3 up-regulated protein (VDUP1) and thioredoxin interacting protein (Txnip), was recently reported to be a key transcriptional factor controlling glucose metabolism. Here, we elucidated the functions of TBP-2 in maintaining blood glucose homeostasis during the fetal period. TBP- $2^{+/-}$female mice were mated with $\mathrm{TBP}-2^{+/-}$male mice; beginning 16.5 -d post coitum, pregnant mice were fed or fasted for $24 \mathrm{~h}$. Under conditions of maternal starvation, the blood glucose levels of TBP-2 $2^{-1-}$ fetuses were significantly lower than those of TBP $-2^{+/+}$fetuses, corresponding to the elevated plasma insulin levels of $\mathrm{TBP}-2^{-/-}$fetuses compared with those of $\mathrm{TBP}-2^{+/+}$ fetuses. There was no difference between TBP $-2^{+/+}$and TBP- $2^{-/-}$ fetuses in terms of their pancreatic $\beta$-cell masses or the expression of placental glucose transporters under conditions of either maternal feeding or fasting. Thus, during maternal fasting, fetal TBP-2 suppresses excessive insulin secretion to maintain the fetus's glucose levels, implying that TBP-2 is a critical molecule in mediating fetal glucose homeostasis depending on nutrient availability. (Pediatr Res 67: 138-143, 2010)
\end{abstract}

$\mathrm{B}$ ecause glucose is a major fuel for energy metabolism during fetal development, appropriate fetal glucose utilization is indispensable for normal fetal growth. The main source of fetal glucose is the maternal glucose pool, and fetal blood glucose concentration is proportional to maternal blood glucose level $(1,2)$. The fetal blood glucose level is also regulated by the fetus's own insulin, as evidenced by the studies in fetal sheep showing that chronic withdrawal of

Received July 7, 2009; accepted September 21, 2009.

Correspondence: Shigeo Yura, M.D., Ph.D., Department of Gynecology and Obstetrics, Kyoto University Graduate School of Medicine, 54, Shogoin Kawahara-cho, Sakyo-ku, Kyoto 606-8507, Japan; e-mail: psuka@kuhp.kyoto-u.ac.jp

Supported by Grants-in-Aid for Scientific Research from the Ministry of Education, Culture, Sports, Science and Technology, Japan (nos. 15659393, 16390475, 17390450, 17591728, 17591730, 17659513, and 18390446); the Research Grant for Cardiovascular Disease from the Ministry of Health, Labor and Welfare; the Smoking Research Foundation; Takeda Science Foundation; Takeda Medical Research Foundation; The Naito Foundation; Uehara Memorial Foundation; the Food Science Institute Foundation; Precursory Research for Embryonic Science and Technology (PRESTO); and Japan Science and Technology Agency (JST). insulin by streptozotocin injection to the fetus resulted in hypoinsulinemia with hyperglycemia (3-5). Conversely, direct infusion of insulin to the fetus decreases fetal glucose concentration in both sheep and rat fetuses $(6,7)$. Thus, insulin can function as a blood glucose regulator during the fetal period.

In mouse fetuses, the pancreas begins to develop from embryonic day 9.5 (E9.5) (8). Pancreatic endocrine cells are present from the very beginning of pancreatic development (E9.5), whereas the cells that express insulin appear at E10.5. Endocrine cell genesis takes place through E14.5 and results in numerous mature insulin-expressing cells (9). The pancreatic duodenal homeobox gene-1 (Pdx-1) is a master regulator of both pancreatic development and the differentiation of progenitor cells into the $\beta$-cell phenotype (8). During the later stages of islet development, around E17.5, the expression of Pdx-1 becomes mostly restricted to the mature $\beta$-cells of the endocrine pancreas $(10,11)$. Therefore, murine pancreatic $\beta$-cells have the capacity to produce insulin at this relatively late stage of development.

Thioredoxin binding protein-2 (TBP-2) is a $46-\mathrm{kD}$ protein that was identified in a yeast two-hybrid system study. It serves as a negative regulator of thioredoxin, one of the major antioxidant proteins (12). TBP-2 is identical with vitamin D3 up-regulated protein (VDUP1) and thioredoxin interacting protein (Txnip). In addition to its redox regulatory activity, TBP-2 has a wide range of biologic functions in such areas as cell growth/differentiation, apoptosis, immunity, and metabolism (13). Recently, it has been proposed that TBP-2 also has a central role in glucose metabolism. In humans, TBP-2 up-regulation caused by hyperglycemia induces insulin resistance, impairing glucose uptake in skeletal muscles (14). TBP-2 is also associated with $\beta$-cell apoptosis due to glucose toxicity $(15,16)$. TBP-2-deficient mice show marked hypogly-

\footnotetext{
Abbreviations: FBPase, fructose-1,6-bisphosphatase; G6Pase, glucose-6phosphatase; GLUT, glucose transporter; Ins-1, -2, insulin-1, insulin-2; Pdx-1, pancreatic duodenal homeobox gene-1; PEPCK, phosphoenolpyruvate carboxykinase; TBP-2, thioredoxin binding protein-2; TUNEL, terminal deoxynucleotidyl transferase-mediated dUTP-biotin nick end labeling
} 
cemia with hyperinsulinemia under starvation conditions $(17,18)$. It should be noted, however, that all of these studies have focused on adult glucose metabolism, while the function of TBP-2 in glucose metabolism during the fetal period remains unknown.

The purpose of this study, therefore, was to clarify the functions of TBP-2 in regulating blood glucose homeostasis in relation to insulin secretion during the fetal period.

\section{METHODS}

Study design using $\mathbf{T B P}-2^{-/-}$mice. $\mathrm{TBP}-2^{-/-}$mice were generated as described previously (18). Mice were housed individually with free access to water and chow diet during $14 \mathrm{~h} / 10 \mathrm{~h}$ light/dark cycles. All animal experiments used age-matched mice (9-11 wk of age). Heterozygous virgin female mice $\left(\mathrm{TBP}-2^{+/-}\right)$were crossed with heterozygous male mice $\left(\mathrm{TBP}-2^{+/-}\right)$. This cross-yielded wild-type (TBP- $2^{+/+}$), heterozygous type (TBP- $2^{+/-}$), and homozygous type (TBP-2 $2^{-1-}$ ) fetuses. The day of initiation of pregnancy was determined by the presence of a vaginal plug that had formed after an overnight mating and designated as 0.5 -d post coitum (dpc). From 16.5-dpc, pregnant mice were either fasted (Fasted) or fed ad libitum (Fed) for $24 \mathrm{~h}$. At the end of $24 \mathrm{~h}$ of fasting or feeding, pregnant mice were anesthetized with pentobarbital sodium $(125-\mathrm{mg} / \mathrm{kg}$ body weight, s.c.). Fetuses were collected and weighed, and fetal blood was immediately collected from trunk vessels into heparinized tubes. Maternal blood, placentas, and fetal pancreases were also collected, quickly frozen in liquid nitrogen, and stored at $-80^{\circ} \mathrm{C}$. Maternal blood and fetal blood were centrifuged at $3000 \mathrm{rpm}$ for $30 \mathrm{~min}$ and the plasma thus obtained was stored at $-20^{\circ} \mathrm{C}$. For our analysis, we used dams whose litters included at least one TBP- $2^{+/+}$and one TBP- $2^{-1-}$ fetus so that we could compare the phenotypes associated with different genotypes within a litter.

All experimental procedures were approved by the Animal Research Committee, Graduate School of Medicine, Kyoto University (Med Kyo 04116, 05348, 06221).

Measurement of blood glucose. Maternal blood glucose was measured using the Glutest Ace R blood glucose meter (ARKRAY, Kyoto, Japan) with blood obtained by cutting a tail vessel $30 \mathrm{~min}$ after anesthesia. The intra-assay coefficient of variation (CV) was less than $2.5 \%$. Fetal plasma glucose was measured using the L-Type Glucose 2 assay (Wako Pure Chemical Industries, Osaka, Japan), as instructed by the manufacture's instructions. The CVs of the absorbances were less than $2 \%$.

Plasma insulin analysis. Plasma insulin was measured using the Insulin ELISA Kit: Mouse, Ultrasensitive (Morinaga Institute of Biologic Science, Yokohama City, Japan) as instructed by the manufacture's instructions. The intra-assay CV was less than $10 \%$.

Plasma lactate analysis. Plasma lactate was measured using the Determiner LA kit (Kyowa Medex, Tokyo, Japan) according to the manufacturer's instructions. The intra-assay CV was less than 5\%.

Immunohistochemistry. Fetal pancreases were fixed in 10\% formaldehyde and embedded in paraffin, and then 5- $\mu \mathrm{m}$-thick sections were cut from the paraffin blocks. The tissue sections were deparaffinized and dehydrated. Immunohistochemical staining for insulin and TBP-2 was performed using the high-polymer method with some modifications. The sections were incubated in 3\% hydrogen peroxide for $10 \mathrm{~min}$ at room temperature to quench endogenous peroxidase activity. For detection of TBP-2, the sections were incubated with mouse monoclonal anti-Txnip antibody (K0205-3; Medical \& Biologic Laboratories, Nagoya, Japan; 1:100 dilution) at room temperature for $1 \mathrm{~h}$. Then the sections were incubated with Histofine Simple Stain Mouse MAX-PO (M) (Nichirei Bioscience, Tokyo, Japan) at room temperature for $30 \mathrm{~min}$. For detection of insulin, the sections were then incubated with a rabbit polyclonal anti-insulin antibody (sc-9168; Santa Cruz Biotechnology, Santa Cruz, CA; 1:50 dilution) at room temperature for $1 \mathrm{~h}$. Then the sections were incubated with Histofine Simple Stain Mouse MAX-PO (R) (Nichirei Bioscience) at room temperature for $30 \mathrm{~min}$. Then, peroxidase activity was visualized by treatment with diaminobenzidine (Simple Stain DAB solution, Nichirei Bioscience) for 4 min. Nuclei were counterstained with Mayer's hematoxylin. The sections were then dehydrated, cleared, and mounted.

Apoptosis detection. Apoptotic cells in fetal pancreas were detected using ApopTag In Situ Apoptosis Detection Kits (Chemicon-Millipore, Billerica, MA), which label apoptotic cells by modifying DNA fragments utilizing terminal deoxynucleotidyl transferase (TdT)-mediated dUTP-biotin nick end labeling (TUNEL), according to the manufacturer's instructions. Nuclei were counterstained with methyl green.
Primers and probes. We used the primer and Fam-MGB probe sets for the TaqMan Gene Expression Assays [Txnip: Mm00452393 m1, Insulin-1 (Ins-1): Mm01259683 g1, Insulin-2 (Ins-2): Mm00731595 gH, Pdx-1: Mm00435565 m1, phosphoenolpyruvate carboxykinase (PEPCK): Mm00440636 m1, fructose-1,6bisphosphatase (FBPase): Mm00490181 m1, and glucose-6-phosphatase (G6Pase): Mm00616234 m1; Applied Biosystems]. As a housekeeping gene, we used the primer and Vic/Tamra probe sets for TaqMan Ribosomal RNA Control Reagents (product number: 4308329, Applied Biosystems).

Quantitative RT-PCR analysis. Total RNA was extracted from placentas using Sepasol reagent (Nacalai Tesque, Kyoto, Japan) according to the manufacturer's instructions. mRNA expression was quantified using the ABI Prism 7000 Sequence Detection System (Applied Biosystems, Foster City, CA) utilizing TaqMan technology as previously described $(19,20)$. Briefly, reverse transcription and PCR were performed using a one-step methodology. A CT value, which represents the number of cycles necessary to reach the threshold, was identified for each reaction. For quantification of gene expression, we used the standard curve method. CT values were used to read off relative RNA amounts. An mRNA expression value was then obtained by dividing the value for TBP-2, Ins-1, Ins-2, Pdx-1, PEPCK, FBPase, or G6Pase by the value for Ribosomal RNA. All samples were run in duplicate.

Western blots. Protein extraction, SDS-PAGE, and immunoblotting were performed as previously described (21). Briefly, homogenized proteins were fractioned using SDS-PAGE and transferred to an Immobilon P membrane (Millipore, Billerica, MA). For immunodetection, we used rabbit polyclonal antibody against Glucose Transporter GLUT1 (ab14683, Abcam, Cambridge, MA), Glucose Transporter GLUT3 (ab41525, Abcam), and beta ActinLoading Control (ab8227, Abcam). For the secondary antibody, we used horseradish peroxidase (HRP)-conjugated goat anti-rabbit antibody (sc-2054, Santa Cruz Biotechnology). The signal was detected by chemiluminescence (Amersham ECL Plus Western Blotting Detection Kit, GE Healthcare BioSciences, Uppsala, Sweden) with exposure to Amersham Hyperfilm ECL (GE Healthcare Bio-Sciences). The intensity of bands was quantified through densitometry using ImageJ software (National Institutes of Health).

Statistical analysis. Values were expressed as means +/- SEM. Data were analyzed using either unpaired $t$ test or one-way ANOVA followed by the Student-Newman-Keuls test. For analysis of fetal blood glucose or insulin, we used a paired $t$ test. This is because individual maternal blood glucose levels vary, so that the fetal blood glucose levels in one litter could be very different from those in another litter even when the two fetuses had the same genotype. For this reason, we compared blood glucose levels among littermates, by averaging the blood glucose levels of all TBP- $2^{+/+}$fetuses within a litter and those of all TBP- $2^{-/-}$fetuses within the same litter. Then, each TBP- $2^{+/+}$ average was compared with the TBP- $2^{-1-}$ average from the same litter by paired $t$ test. To use this paired $t$ test, we excluded TBP- $2^{+/-}$fetuses from analysis, and $p$-values of less than 0.05 were regarded as statistically significant.

\section{RESULTS}

Fetal and placental weights. There was no statistically significant difference in mean litter size between the fed group $(9.6+/-0.8)$ and the fasted group $(8.8+/-0.3)$. Fetal and placental weights were also not significantly different among TBP- $2^{+/+}$, TBP- $2^{+/-}$, and TBP- $2^{-1-}$ fetuses in either the fed or the fasted state. Maternal fasting did not reduce fetal or placental weight in any fetal genotype (Table 1).

Maternal and fetal blood glucose and plasma insulin levels. The blood glucose levels of TBP-2 $2^{+/-}$mothers were markedly reduced by starvation (Fig. $1 A$ ), almost to the degree

Table 1. Fetal and placental weights at 17.5 d post coitum

\begin{tabular}{lrrc}
\hline & $+/+$ & $+/-$ & $-/-$ \\
\hline Fetal weights (mg) & & & \\
$\quad$ Fed & $834 \pm 20$ & $818 \pm 15$ & $797 \pm 14$ \\
$\quad$ Fasted & $787 \pm 19$ & $781 \pm 15$ & $782 \pm 29$ \\
Placental weights (mg) & & & \\
$\quad$ Fed & $105 \pm 4$ & $104 \pm 4$ & $96 \pm 4$ \\
$\quad$ Fasted & $90 \pm 3$ & $89 \pm 3$ & $87 \pm 4$ \\
\hline
\end{tabular}

Values are mean $+/-\mathrm{SEM}$ for fed (TBP- $2^{+/+}, n=18$; $\mathrm{TBP}^{2} 2^{+/-}, n=30$; and TBP- $\left.2^{-l-}, n=19\right)$ and fasted (TBP- $2^{+/+}, n=22$; $\mathrm{TBP}^{-2^{+--}}, n=30$; and TBP- $2^{-1-}, n=9$ ). The data were analyzed using one-way ANOVA. 
A

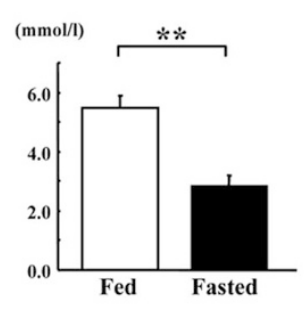

B

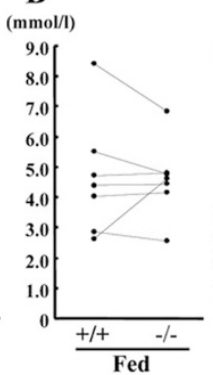

C

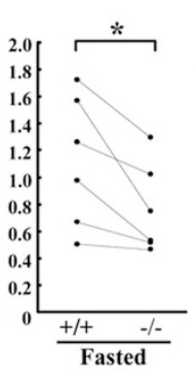

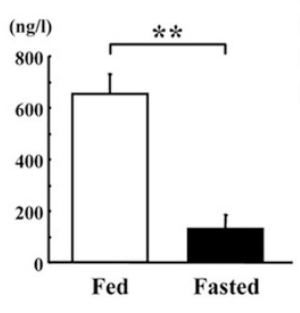

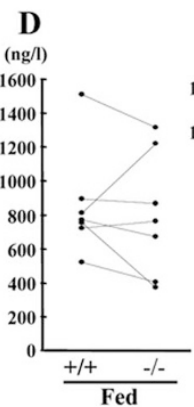

$\mathbf{E}$

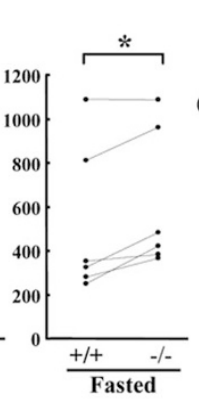

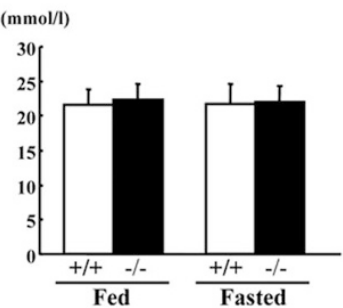

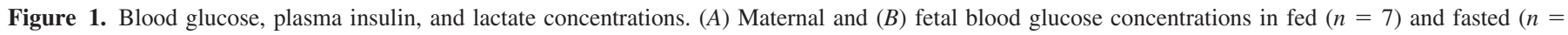

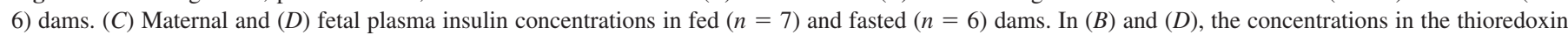

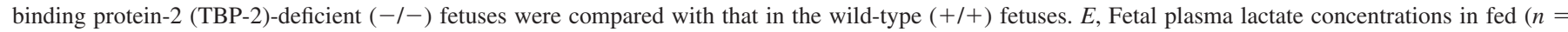

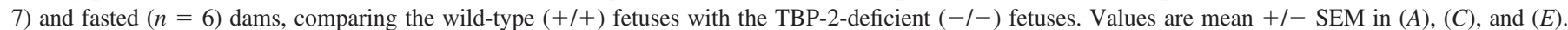

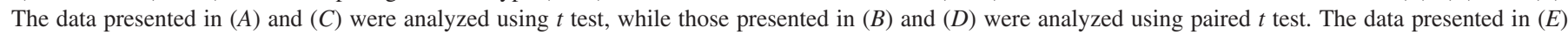
were analyzed using one-way ANOVA. ${ }^{*} p<0.05, * * p<0.01$.

seen in wild-type dams (data not shown). Maternal fasting induced significant fetal hypoglycemia in both genotypes (Fig. $1 B)$. Under the fed condition, there was no difference in blood glucose levels between TBP- $2^{+/+}$and TBP-2 $2^{-/-}$fetuses (4.65 $\pm 0.74 \mathrm{mM}$ and $4.59 \pm 0.48 \mathrm{mM}$, respectively), but under the maternal fasting condition, the blood glucose levels of TBP- $2^{-/-}$fetuses $(0.79 \pm 0.13 \mathrm{mM})$ became significantly lower than those of TBP- $2^{+/+}$fetuses $(1.14 \pm 0.18 \mathrm{mM})($ Fig. $1 B, p=0.0116)$.

Maternal fasting significantly lowered maternal plasma insulin levels; this decrease in insulin corresponded to the simultaneous decrease in blood glucose (Fig. 1C). Maternal fasting also caused significant hypoinsulinemia in fetuses (Fig. $1 D)$. Under the fed condition, there was no difference in plasma insulin levels between TBP- $2^{+/+}$and TBP- $2^{-1-} \mathrm{fe}-$ tuses $(0.85 \pm 0.12 \mathrm{ng} / \mathrm{L}$ and $0.80 \pm 0.19 \mathrm{ng} / \mathrm{L}$, respectively), but under the maternal fasting condition, the plasma insulin levels of TBP-2 $2^{-/-}$fetuses $(0.62 \pm 0.13 \mathrm{ng} / \mathrm{L})$ were significantly higher than those of TBP- $2^{+/+}$fetuses $(0.52 \pm 0.14$ ng/L) (Fig. $1 D, p=0.0196)$.

Fetal plasma lactate level. In fetal plasma, the lactate level was not statistically different between fed and fasted mice or between TBP-2 $2^{+/+}$and TBP-2 $2^{-/-}$mice (Fig. 1E).

Gene and protein expression and $\beta$-cell morphology in the fetal pancreas. In the TBP- $2^{+/+}$fetal pancreas, TBP- 2 immunostaining was observed in the nuclei of islet cells and in the nuclei of exocrine cells, whereas the TBP- $2^{-/-}$fetal pancreas did not show any TBP-2 staining (Fig. 2A). TBP-2 mRNA expression was almost completely absent in the TBP-2 ${ }^{-1-}$ fetal pancreas (Fig. 2B). Among TBP-2 $2^{+/+}$fetuses, TBP-2 mRNA expression in the pancreas was significantly higher in the maternal fasting group than in the fed group (Fig. 2B). There was no difference in the mRNA expression levels of Ins-1 and Ins-2, the insulin gene, or in those of $P d x-1$, between
A
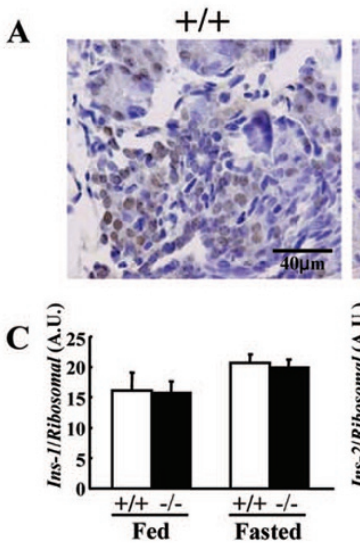
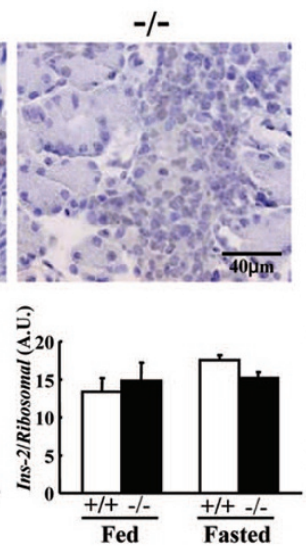
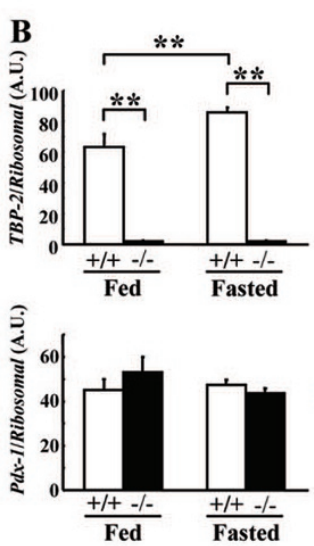

D

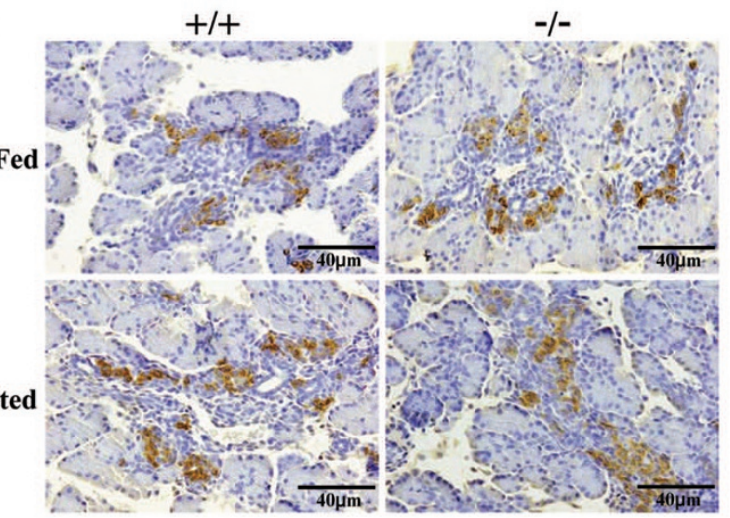

Figure 2. TBP-2 protein expression and TBP-2, Ins-1, Ins-2, and $P d x-1$ mRNA expression levels in the fetal pancreas, and histologic examination of $\beta$-cells. (A) Representative immunostaining of thioredoxin binding protein-2 (TBP-2) in fetal pancreas. TBP-2 expression in the TBP-2-deficient (-/-) fetuses was compared with that in the wild-type $(+/+)$ fetuses in fed state. Original magnification was $\times 400$. Black bars indicate $40 \mu \mathrm{m} .(B, C)$ The mRNA expression levels of (B) TBP-2, (C) Insulin-1 (Ins-1), Insulin-2 (Ins-2), and pancreatic duodenal homeobox gene-1 (Pdx-1) in fetal pancreases of the fed group (TBP-2 ${ }^{+/+}, n=$ $6-8$, and TBP- $\left.2^{-1-}, n=5-8\right)$ and the fasted group (TBP- $2^{+/+}, n=5-9$, and TBP- $\left.2^{-1-}, n=4-7\right)$. Values are mean $+/-$ SEM. The data were analyzed using one-way ANOVA. $* * p<0.01$. (D) Representative pancreatic $\beta$-cells as revealed by insulin immunostaining. Insulin expression in the TBP-2-deficient $(-/-)$ fetuses was compared with that in the wild-type $(+/+)$ fetuses in either fed or fasted state. Original magnification was $\times 400$. Black bars indicate $40 \mu \mathrm{m}$. 


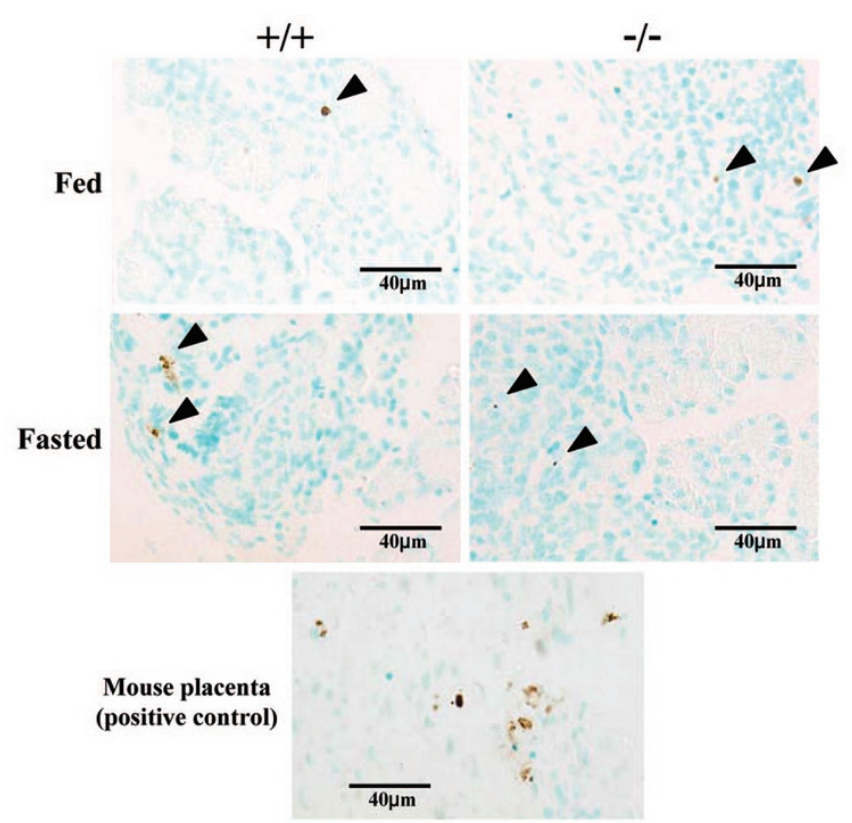

Figure 3. Apoptosis of fetal pancreas. Representative pancreatic $\beta$-cells as revealed by terminal deoxynucleotidyl transferase-mediated dUTP-biotin nick end labeling (TUNEL) method. Apoptotic cells in the thioredoxin binding protein-2 (TBP-2)-deficient ( $-/-$ ) fetuses were compared with those in the wild-type $(+/+)$ fetuses in either fed or fasted state. Arrowhead indicates apoptotic cell. We used murine placenta as a positive control. Original magnification was $\times 400$. Black bars indicate $40 \mu \mathrm{m}$.
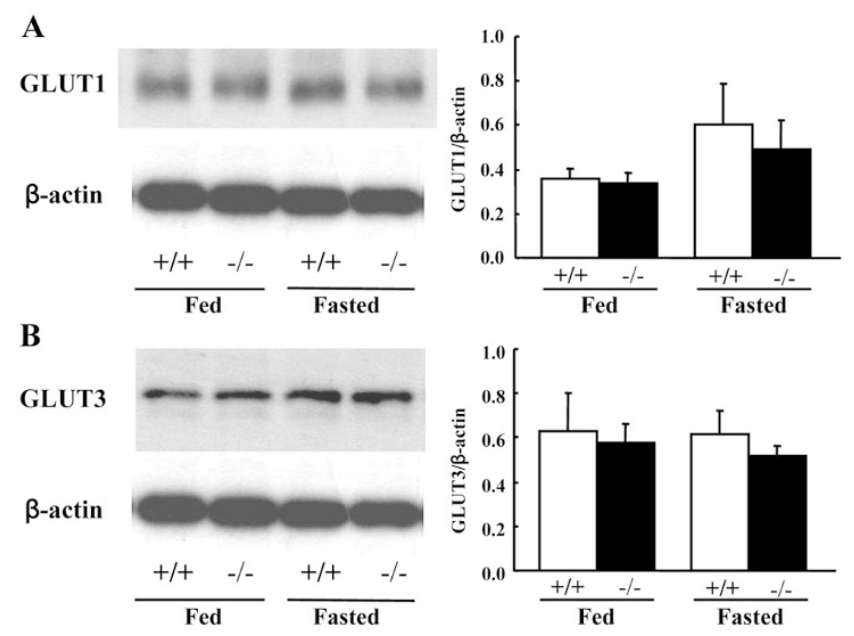

Figure 4. GLUT1 and GLUT3 protein expression levels in placenta. Representative Western blots of $(A)$ Glucose Transporter 1 (GLUT1) and $(B)$ Glucose Transporter 3 (GLUT3) in placentas of the fed group (TBP- $2^{+/+}, n=$ 5 , and TBP- $2^{-/-}, n=5$ ) and the fasted group (TBP- $2^{+/+}, n=5$, and TBP- $\left.2^{-\prime-}, n=5\right)$. The graphs show quantification of the band intensities of GLUT1 and GLUT3 by densitometric analysis, divided by the band intensity of $\beta$-actin. The data were analyzed using one-way ANOVA.

TBP- $2^{+/+}$and TBP- $2^{-/-}$in either the fed or the fasted state (Fig. $2 C$ ). Moreover, there were no differences in $\beta$-cell mass among the four groups (Fig. 2D). In the TUNEL assay, there was minimal apoptosis in the fetal pancreas, and there was no apparent difference among TBP- $2^{+/+}$and TBP- $2^{-1-}$ in either the fed or fasted fetuses (Fig. 3).

Expression levels of placental glucose transporter $(\boldsymbol{G L U})$. There was no difference in GLUT1 or GLUT3 protein expression in the placenta between $\mathrm{TBP}-2^{+/+}$and TBP- $2^{-1-}$ fetuses in either the fed or the fasted group, which suggests that glucose transport across the placenta was not affected by the presence or absence of the TBP-2 gene (Fig. 4).

Expressions of gluconeogenic genes in the fetal liver. The mRNA expression of the gluconeogenic genes (PEPCK, FBPase, and G6Pase) in the fetal livers tended to be higher by maternal starvation (Fig. 5). TBP- $2^{+/+}$and TBP- $2^{-/-}$fetuses subjected to maternal fasting exhibited no differences in mRNA expression of these genes (Fig. 5).

\section{DISCUSSION}

In this study, we first demonstrated that TBP-2 is a critical blood glucose regulator during the fetal period, particularly when the dam becomes hypoglycemic. The low blood glucose concentrations seen in TBP- $2^{-1-}$ fetuses subjected to maternal starvation were accompanied by relative hyperinsulinemia. Because fetal insulin is one of the regulators of the fetus's blood glucose level $(3-5,7)$, our results indicate that TBP-2 suppresses the plasma insulin level to maintain fetal blood glucose homeostasis when maternally derived energy is inadequate and thus to protect the fetus from harmful hypoglycemia. When maternal food intake is sufficient, TBP- $2^{+/+}$and TBP- $2^{-/-}$fetuses exhibit similar blood glucose levels, suggesting that the TBP-2 gene is silent when enough energy is available. Therefore, TBP-2 is a critical molecule in the physiologic adaptation to fasting.

In adult TBP-2-deficient mice, hyperinsulinemic hypoglycemia has been reported as a result of fasting $(17,18,22)$. As for the fetal period, however, its metabolic changes have not yet been studied in mice of this genotype. Murine $\beta$-cells are already functioning at E16.5-E17.5, making it possible that the hypoglycemia observed in TBP-2-deficient fetuses is induced by the action of fetal $\beta$-cells. On the basis of this possibility, we reproduced in fetal TBP-2-deficient mice a hyperinsulinemic hypoglycemia similar to that seen in TBP2-deficient adult mice. The present findings suggest that the regulation of insulin secretion by TBP-2 is already functioning before birth.

We have observed in another study that the forced expression of TBP-2 suppresses glucose-stimulated insulin secretion, whereas the knockdown of TBP-2 augments glucose-induced insulin secretion in INS-1 (rat insulinoma $\beta$-cells) in vitro (Yoshihara et al., manuscript in preparation). Minn et al. (23) reported the same finding as ours, namely, that over-expression of Txnip repressed insulin secretion in INS-1. This evidence is compatible with our finding that $\mathrm{TBP}-2^{-1-}$ fetuses showed higher plasma insulin levels during maternal starvation.

Regarding the molecular mechanism of increased insulin secretion in TBP- $2^{-1-}$ mice, we speculate that TBP-2 might regulate the reduction-oxidation (redox) status in pancreatic $\beta$-cells. It is known that lactate levels reflect the cellular status of NADH/NAD, which regulates insulin release. Although the lactate level in fetal plasma was not statistically different between feeding and fasting or between the TBP- $2^{+/+}$and TBP- $2^{-1-}$ groups in our study, the "cytoplasmic" lactate level might be affected by feeding status (i.e. fasting versus feed- 

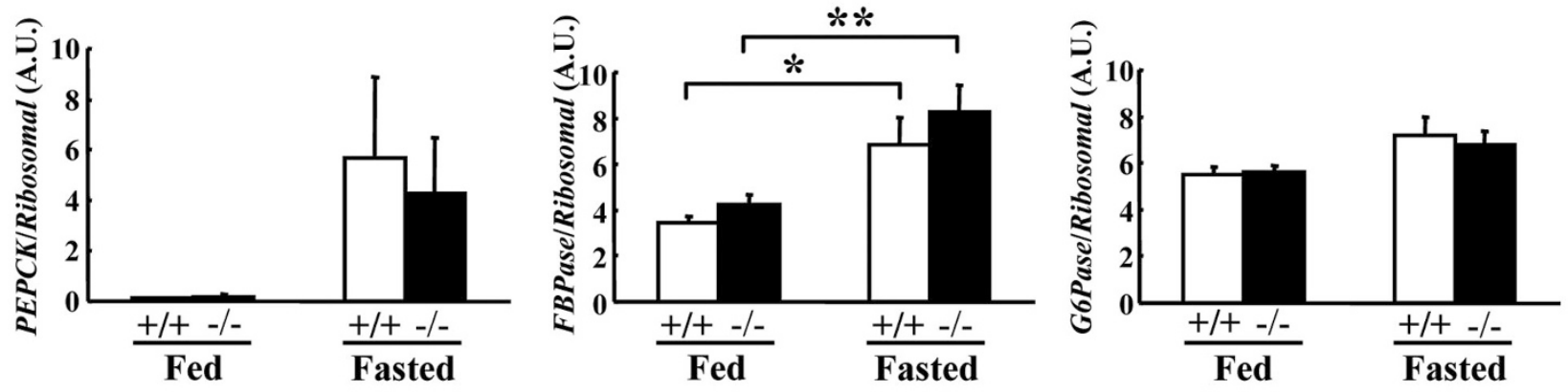

Figure 5. mRNA expression levels of gluconeogenic genes in the fetal liver. The mRNA expression levels of phosphoenolpyruvate carboxykinase (PEPCK), fructose-1,6-bisphosphatase (FBPase), and glucose-6-phosphatase (G6Pase) in fetal liver of the fed group (TBP-2 ${ }^{+/+}, n=4$, and TBP-2 $2^{-/-}, n=5$ ) and the fasted group (TBP- $2^{+/+}, n=4$, and TBP- $2^{-/-}, n=5$ ). Values are mean $+/-$ SEM. The data were analyzed using one-way ANOVA. * $p<0.05, * * p<0.01$.

ing). Ivarsson et al. (24) showed that NADH/NAD status in pancreatic $\beta$-cells affects the exocytosis of insulin granules. Moreover, they showed that this redox regulatory system is further regulated by TBP-2. Considering the fact that TBP-2 is a negative regulator of thioredoxin, which is a dominant antioxidant protein, TBP-2 might control insulin secretion through redox regulation. This possibility is now under investigation in our laboratory.

In the fed state, there were no significant differences in pancreatic $\beta$-cell mass, apoptosis, or pancreatic mRNA expression of Ins-1, Ins-2, and $P d x-1$ between TBP-2 ${ }^{+/+}$fetuses and TBP-2 $2^{-1-}$ fetuses, which implies that TBP-2 does not affect $\beta$-cell differentiation, proliferation, or apoptosis in the physiologically developing pancreas. It has been reported that older TBP-2-deficient mice (9-mo-old TXNIP nonsense mutation mice) have larger pancreatic $\beta$-cell masses than wildtype mice of the same age have (25). No such $\beta$-cell mass enlargement was observed in TBP- $2^{-1-}$ fetal pancreases in our study. We further observed that maternal fasting did not change either the pancreatic $\beta$-cell mass, apoptosis, or the mRNA expression of Ins-1, Ins-2, and $P d x-1$ in TBP-2 $2^{-1-}$ fetuses. Therefore, we concluded that the relative hyperinsulinemia observed in fasted TBP-2-deficient fetuses was not due to the change of $\beta$-cell mass.

Glucose transport from mother to fetus is mediated by the placental glucose transporters GLUT1 and GLUT3, through facilitated diffusion down a concentration gradient (26). We demonstrated that maternal feeding status did not affect the expression levels of the placental glucose transporters in any fetal genotypes, and thus that glucose transfer from mother to fetuses might not be affected by fetal/placental genotype.

The mRNA expression of the gluconeogenic genes (PEPCK, FBPase, and G6Pase) in the fetal livers of the mice in this study tended to be higher in the maternal starvation group, but there was no difference between the TBP- $2^{+/+}$and TBP- $2^{-1-}$ groups in their expression. In adult TBP-2-deficient mice, however, impaired hepatic glucose production has been observed despite equivalent mRNA expression of G6Pase and PEPCK (27), so that there remains the possibility that insufficient gluconeogenesis may contribute to the hypoglycemia observed in TBP-2 deficient fetuses. We cannot make a definite conclusion on this matter at the present time.
As for peripheral glucose utilization, we and others have found that TBP-2 deficiency increased peripheral glucose uptake in insulin-dependent pathway $(17,22,28)$. On the other hand, enhanced glucose uptake in an insulin-independent manner has been also demonstrated in Txnip-silenced adipocytes and skeletal muscle (14). These data lead us the belief that enhanced peripheral glucose uptake might also contribute to the lower blood glucose levels observed in TBP-2-deleted fetuses.

TBP-2 responds to high-glucose stimulation; this is explained by the evidence showing that the promoter region of the TBP-2 gene includes a carbohydrate response element (16). In contrast, it is unclear how TBP-2 responds to a low-glucose or low-energy state. We observed that maternal food restriction leads to an elevation of maternal plasma glucocorticoid levels, which leads in turn to a marked elevation in fetal plasma glucocorticoid levels (Ref. 29 and Mogami, unpublished observation). This implies that elevated blood glucocorticoid levels caused by starvation turns on TBP-2 transcription, which leads to the suppression of insulin secretion. In addition, TBP-2 deficiency does not increase plasma insulin concentration when adequate glucose is present. It is also possible that regulation of insulin secretion by TBP-2 depends on an intracellular signal that is activated only when glucose supply is diminished.

In conclusion, TBP-2 expression is up-regulated in fetal pancreases responding to energy deprivation due to maternal fasting. TBP-2 suppresses excessive insulin secretion to maintain the blood glucose level. Thus, TBP-2 is a critical component in the maintenance of fetal glucose homeostasis depending on nutrient availability.

Acknowledgments. We thank Dr. Hiroshi Masutani, Dr. Eiji Yoshihara, and Dr. Rie Watanabe for informative discussion. We acknowledge Ms. Akiko Abe and Ms. Miki Tatebayashi for secretarial and technical assistance.

\section{REFERENCES}

1. Ashmead GG, Kalhan SC, Lazebnik N, Nuamah IF 1993 Maternal-fetal substrate relationships in the third trimester in human pregnancy. Gynecol Obstet Invest $35: 18-22$

2. Whaley WH, Zuspan FP, Nelson GH 1966 Correlation between maternal and fetal plasma levels of glucose and free fatty acids. Am J Obstet Gynecol 94:419-421 
3. Hay WW Jr, Meznarich HK 1988 Use of fetal streptozotocin injection to determine the role of normal levels of fetal insulin in regulating uteroplacental and umbilical glucose exchange. Pediatr Res 24:312-317

4. Hay WW Jr, Meznarich HK, Fowden AL 1989 The effects of streptozotocin on rates of glucose utilization, oxidation, and production in the sheep fetus. Metabolism 38:30-37

5. Philipps AF, Rosenkrantz TS, Grunnet ML, Connolly ME, Porte PJ, Raye JR 1986 Effects of fetal insulin secretory deficiency on metabolism in fetal lamb. Diabetes 35:964-972

6. Leturque A, Revelli JP, Hauguel S, Kande J, Girard J 1987 Hyperglycemia and hyperinsulinemia increase glucose utilization in fetal rat tissues. Am J Physiol 253:E616-E620

7. Simmons MA, Jones MD Jr, Battaglia FC, Meschia G 1978 Insulin effect on fetal glucose utilization. Pediatr Res 12:90-92

8. Habener JF, Kemp DM, Thomas MK 2005 Minireview: transcriptional regulation in pancreatic development. Endocrinology 146:1025-1034

9. Collombat P, Hecksher-Sorensen J, Serup P, Mansouri A 2006 Specifying pancreatic endocrine cell fates. Mech Dev 123:501-512

10. Guz Y, Montminy MR, Stein R, Leonard J, Gamer LW, Wright CV, Teitelman G 1995 Expression of murine STF-1, a putative insulin gene transcription factor, in beta cells of pancreas, duodenal epithelium and pancreatic exocrine and endocrine progenitors during ontogeny. Development 121:11-18

11. Offield MF, Jetton TL, Labosky PA, Ray M, Stein RW, Magnuson MA, Hogan BL, Wright CV 1996 PDX-1 is required for pancreatic outgrowth and differentiation of the rostral duodenum. Development 122:983-995

12. Nishiyama A, Matsui M, Iwata S, Hirota K, Masutani H, Nakamura H, Takagi Y, Sono H, Gon Y, Yodoi J 1999 Identification of thioredoxin-binding protein-2/ vitamin $\mathrm{D}(3)$ up-regulated protein 1 as a negative regulator of thioredoxin function and expression. J Biol Chem 274:21645-21650

13. Kaimul AM, Nakamura H, Masutani H, Yodoi J 2007 Thioredoxin and thioredoxinbinding protein-2 in cancer and metabolic syndrome. Free Radic Biol Med 43:861868

14. Parikh H, Carlsson E, Chutkow WA, Johansson LE, Storgaard H, Poulsen P, Saxena R, Ladd C, Schulze PC, Mazzini MJ, Jensen CB, Krook A, Bjornholm M, Tornqvist H, Zierath JR, Ridderstrale M, Altshuler D, Lee RT, Vaag A, Groop LC, Mootha VK 2007 TXNIP regulates peripheral glucose metabolism in humans. PLoS Med 4:e158

15. Chen J, Saxena G, Mungrue IN, Lusis AJ, Shalev A 2008 Thioredoxin-interacting protein: a critical link between glucose toxicity and beta-cell apoptosis. Diabetes 57:938-944

16. Minn AH, Hafele C, Shalev A 2005 Thioredoxin-interacting protein is stimulated by glucose through a carbohydrate response element and induces beta-cell apoptosis. Endocrinology 146:2397-2405

17. Hui TY, Sheth SS, Diffley JM, Potter DW, Lusis AJ, Attie AD, Davis RA 2004 Mice lacking thioredoxin-interacting protein provide evidence linking cellular redox state to appropriate response to nutritional signals. J Biol Chem 279:24387-24393
18. Oka S, Liu W, Masutani H, Hirata H, Shinkai Y, Yamada S, Yoshida T, Nakamura H, Yodoi J 2006 Impaired fatty acid utilization in thioredoxin binding protein-2 (TBP-2)-deficient mice: a unique animal model of Reye syndrome. FASEB J 20:121-123

19. Kawamura M, Itoh H, Yura S, Mogami H, Suga S, Makino H, Miyamoto Y, Yoshimasa Y, Sagawa N, Fujii S 2007 Undernutrition in utero augments systolic blood pressure and cardiac remodeling in adult mouse offspring: possible involvement of local cardiac angiotensin system in developmental origins of cardiovascular disease. Endocrinology 148:1218-1225

20. Mogami H, Yura S, Itoh H, Kawamura M, Fujii T, Suzuki A, Aoe S, Ogawa Y, Sagawa N, Konishi I, Fujii S 2009 Isocaloric high-protein diet as well as branchedchain amino acids supplemented diet partially alleviates adverse consequences of maternal undernutrition on fetal growth. Growth Horm IGF Res 19:478-485

21. Itoh H, Bird IM, Nakao K, Magness RR 1998 Pregnancy increases soluble and particulate guanylate cyclases and decreases the clearance receptor of natriuretic peptides in ovine uterine, but not systemic, arteries. Endocrinology 139:3329-3341

22. Oka S, Yoshihara E, Bizen-Abe A, Liu W, Watanabe M, Yodoi J, Masutani H 2009 Thioredoxin binding protein-2/thioredoxin-interacting protein is a critical regulator of insulin secretion and peroxisome proliferator-activated receptor function. Endocrinology 150:1225-1234

23. Minn AH, Pise-Masison CA, Radonovich M, Brady JN, Wang P, Kendziorski C, Shalev A 2005 Gene expression profiling in INS-1 cells overexpressing thioredoxininteracting protein. Biochem Biophys Res Commun 336:770-778

24. Ivarsson R, Quintens R, Dejonghe S, Tsukamoto K, in't Veld P, Renstrom E, Schuit FC 2005 Redox control of exocytosis: regulatory role of NADPH, thioredoxin, and glutaredoxin. Diabetes 54:2132-2142

25. Chen J, Hui ST, Couto FM, Mungrue IN, Davis DB, Attie AD, Lusis AJ, Davis RA, Shalev A 2008 Thioredoxin-interacting protein deficiency induces Akt/Bcl-xL signaling and pancreatic beta-cell mass and protects against diabetes. FASEB J 22:3581-3594

26. Illsley NP 2000 Glucose transporters in the human placenta. Placenta 21:14-22

27. Chutkow WA, Patwari P, Yoshioka J, Lee RT 2008 Thioredoxin-interacting protein (Txnip) is a critical regulator of hepatic glucose production. J Biol Chem 283:23972406

28. Hui ST, Andres AM, Miller AK, Spann NJ, Potter DW, Post NM, Chen AZ, Sachithanantham S, Jung DY, Kim JK, Davis RA 2008 Txnip balances metabolic and growth signaling via PTEN disulfide reduction. Proc Natl Acad Sci USA 105:3921-3926

29. Kawamura M, Itoh H, Yura S, Mogami H, Fujii T, Makino H, Miyamoto $Y$, Yoshimasa Y, Aoe S, Ogawa Y, Sagawa N, Kanayama N, Konishi I 2009 Isocaloric high-protein diet ameliorates systolic blood pressure increase and cardiac remodeling caused by maternal caloric restriction in adult mouse offspring. Endocr $\mathrm{J}$ 56:679-689 